\title{
Effects of plant density and nitrogen fertilization in winter wheat (Triticum aestivum L.). 2. Incidence of Gerlachia nivalis and Fusarium spp. related to yield losses
}

\author{
J. Ellen ${ }^{1}$ and C. J. Langerak ${ }^{2}$ \\ ${ }^{1}$ Department of Field Crops and Grassland Science, Agricultural University, Haar- \\ weg 333, $6709 \mathrm{RZ}$ Wageningen, Netherlands \\ ${ }^{2}$ Government Seed Testing Station, P.O. Box 9104, 6700 HE Wageningen, \\ Netherlands
}

Received 23 December 1985; accepted 26 February 1987

Key words: winter wheat, Gerlachia nivalis, Fusarium spp., plant density, nitrogen, split dressing

\section{Abstract}

The effects of plant density and nitrogen treatment on the infection of grains by Gerlachia nivalis and Fusarium spp. were studied.

At the low plant density there was more infection by G. nivalis and Fusarium spp. than at the high plant density. In the post-floral period this effect was reflected in a more severe attack of the vegetative plant parts and a greater number of grains being infected at the time of harvest.

Delaying the first $\mathrm{N}$ dressings and/or the supplementary nitrogen fertilizations at a later stage in the growing season enhanced the attack by $G$. nivalis and Fusarium spp., G. nivalis was most important; $75 \%$ of the attacked grains were infected by this fungus.

\section{Introduction}

From the literature it appears that many Fusarium species and Gerlachia nivalis, teleomorph Monographella nivalis (Gams \& Muller, 1980) are classified among the weakness fungi (Ubels, 1981). A snow cover in the winter and a wet summer are mentioned by Hewett (1965) as conditions that favour $G$. nivalis attack of seeds in the ears. This fungus develops better in cool and humid environments, whereas $\mathrm{Fu}$ sarium culmorum and Fusarium graminearum prefer a higher temperature and drier weather (Cook, 1980; Cook \& Christen, 1976).

The fungi mentioned above can infect many of the Gramineae, causing damage to plants during practically all growing stages. Infected seeds germinate poorly if at all. Infected seedlings show browning of the coleoptiles, which impedes tiller initia- 
tion (Millar \& Colhoun, 1969). Besides, infection may be expected when the crown roots emerge, resulting in wounds on the nodes. This in turn opens the way to attack by the fungus Fusarium culmorum (Cook, 1968). G. nivalis can cause greyishgreen, watery spots on the leaves and thus reduces the assimilatory area (Richardson \& Zillinsky, 1972). Forrer et al. (1982) often discovered in the centre of leaf spots, caused by mildew (Erysiphe graminis), infections with Fusarium spp. They think that Fusarium spp. may also penetrate through lesions on the leaves caused by other fungi. Infection of the ears takes chiefly place via the inflorescence. The fungus can enter the open florets via the protruding dead anthers (Strange \& Smith, 1971). If it reaches the individual florets, the fungus also gets into the rachis, and the vascular system becomes infected. The transport of assimilates slows down (Ubels, 1981) and further grain development becomes practically impossible. This may result in considerable yield losses (Häni, 1977). Infection and weakening of the grains may be disastrous for the production of sowing seed.

Ubels (1981) states that W. European wheat cultivars, which are already very susceptible to G. nivalis and Fusarium spp., may be predisposed to a more severe infection if plant density is high. These fungi may be favoured by the wheat's greater sensitivity to moisture deficiency, by a different microclimate, by shorter wheat cultivars, by a narrower crop rotation, or by the introduction of broad-spectrum fungicides against other pathogenic fungi of wheat.

In experiments of Cook (1980), low and high doses of nitrogen had varying effects on infections by $F$. culmorum, depending on irrigation. With increasing nitrogen doses, Smiley et al. (1972) found more foot rot caused by Fusarium spp.

This paper aims at illustrating the effects of plant density and nitrogen fertilization on development of $G$. nivalis and Fusarium spp. in winter wheat, because certain effects were observed in a field experiment in 1980.

\section{Methods}

The experimental design, the growing conditions and the sampling procedures have been described in a previous publication (Ellen, 1987). To recapitulate, a winter wheat experiment (cv. Arminda) was laid out side by side in a randomized block design in the Flevopolder. The sowing date was 8 October 1979 and the seed rates were 45 (S1) and 125 (S2) $\mathrm{kg}$ per ha. The distance between rows was $15 \mathrm{~cm}$. The grains were treated with Neo-Voronit. The nitrogen fertilizer was fixed at 140 $\mathrm{kg} / \mathrm{ha}$; the mode of application was characterized by delaying the first nitrogen dressing (Ellen, 1987).

The experiment was sprayed with fungicides in the stages 27 (10 April) and 57 (9 June). In stage 27 Bavistin M (43\% maneb and $6 \%$ carbendazim) was sprayed against Pseudocercosporella herpotrichoides and Mycosphaerella graminicola (stat.con. Septoria tritici) at a rate of $4 \mathrm{~kg} / \mathrm{ha}$. In stage 57 Tilt (25\% triazol) was applied against Puccinia recondita and Leptosphaeria nodorum (stat.con. Septoria nodorum) at a rate of $0.51 /$ ha. On 9 July, 0.51 Pirimor (pirimicarb $50 \%$ ) per ha was sprayed to control aphids.

Weed control was done in stage 30 with 41 MCPA and 41 MCPP per ha; simulta- 
neously 1.51 chlormequat (CCC) was added per ha as a growth regulator.

In addition to the observations on crop agronomy, the attack of peduncle and the sheats of the flag leaves by Fusarium spp. and G. nivalis was assessed on 24 July and expressed as a percentage of the areas of these plant parts infected. On that date determination of the infected leaves was not longer possible, because about half the number of flag leaves had died. At that time also Septoria nodorum and S. tritici must have been present in the crop. Nevertheless, mainly G. nivalis and Fusarium spp. were isolated by the Plant Protection Service from the flag leaf and the flag leaf sheath and peduncle in samples taken on 24 July. This late assessment was due to unfamiliarity with the symptoms.

Finally, $2 \mathrm{~kg}$ of the combine-harvested grain per plot was reserved for assessment of the incidence of $G$. nivalis and Fusarium spp. This test was done at the Government Seed Testing Station in Wageningen applying the following methods.

- Blotter test. 4 sub-samples, each of 50 grains, were germinated between uniformly moist used sheets of filter paper. After 4 days of incubation at $10^{\circ} \mathrm{C}$ and 3 days at $20^{\circ} \mathrm{C}$ (in the dark) the damage to roots and/or germination was scored.

- Agar test. This is a qualitative determination to ascertain which species of Fusari$u m$ and/or $G$. nivalis are present. Per sub-sample, 5 petri dishes with 10 grains each were tested. The grains were plated in petri dishes containing potato dextrose agar $+100 \mu \mathrm{g} / \mathrm{ml}$ streptomycinsulphate $+0.2 \%$ ox-gall. These were incubated for 5 days at $20^{\circ} \mathrm{C}$ in the dark and 3 days at $20^{\circ} \mathrm{C}$ under $12 \mathrm{~h} \mathrm{NUV} \mathrm{per} \mathrm{day} \mathrm{(=} \mathrm{near} \mathrm{ultra-}$ violet light, maximum emission at $\lambda=365.5 \mathrm{~nm}$ ). Scoring was done by counting the seeds that showed development of Fusarium spp. and/or G. nivalis.

\section{Results}

Relation between plant density and infection by G. nivalis and Fusarium spp.

The results of both the filter paper and the agar techniques showed a clear difference in infection of the grains by $G$. nivalis and Fusarium spp. in relation to plant density (Fig. 1). Averaged over the $\mathrm{N}$ treatments, the infection at low plant density was about $1.5 \%(P \leqslant 0.10)$ higher than at high plant density, according to the blotter test, and about $7 \%(P \leqslant 0.05)$ higher according to the agar test. Our observations indicated that about $75 \%$ of the attacked grains were infected by $G$. nivalis.

After flowering the moisture content of ears from the high plant density plots was about $1.5 \%$ lower than that of ears from the low plant density plots (Fig. 2); a similar difference could be found for the whole shoot (stems, leaves and ears). The differences were significant $(P \leqslant 0.05)$ on $17 / 6$ and $1 / 7$ and nearly significant thereafter. On 29 July the crop was still producing but periodic sampling finished. In this experiment the ears ripened somewhat faster than the straw.

Lower plant density gave fewer shoots per $\mathrm{m}^{2}$ (Ellen, 1987). Though receiving the same $\mathrm{N}$ treatment, the nitrogen uptake (in $\mathrm{mg} / \mathrm{shoot}$ ) at the lower plant density was higher (Ellen, 1987). This pattern was less apparent in the $\mathrm{N}$ content of the grains (Table 1). At the lower plant density the green stage of the shoots lasted longer. This, plus the generally high $\mathbf{N}$ content, may have contributed to the greater incidence of $G$. nivalis and Fusarium spp. in the sheaths of the flag leaves, the pe- 
Table $1 . \mathrm{N}$ content $(\%)$ in the kernels $(12 / 8 / 80)$.

\begin{tabular}{|c|c|c|c|c|c|c|}
\hline \multirow[t]{2}{*}{ Sowing rate } & \multicolumn{6}{|c|}{$\mathrm{N}$-treatment } \\
\hline & $\mathrm{N} 1$ & $\mathrm{~N} 2$ & N3 & $\mathrm{N} 4$ & N5 & N6 \\
\hline $\mathrm{S} 1$ & 2.17 & 2.34 & 2.37 & 2.39 & 2.33 & 2.44 \\
\hline$\$ 2$ & 2.17 & 2.40 & 2.65 & 2.50 & 2.49 & 2.40 \\
\hline
\end{tabular}

duncles (Table 2) and the grains (Fig. 1).

Differences in moisture content of the ears as a result of $\mathrm{N}$ treatments were small. The greatest range being on 15 July was from $59.3 \%$ to $62.5 \%$ for S1 and from $59.1 \%$ to $60.8 \%$ for S2 (in both plant densities at N1 and N6 respectively). The moisture content of the ears in the other $\mathrm{N}$ treatments was always between these values.

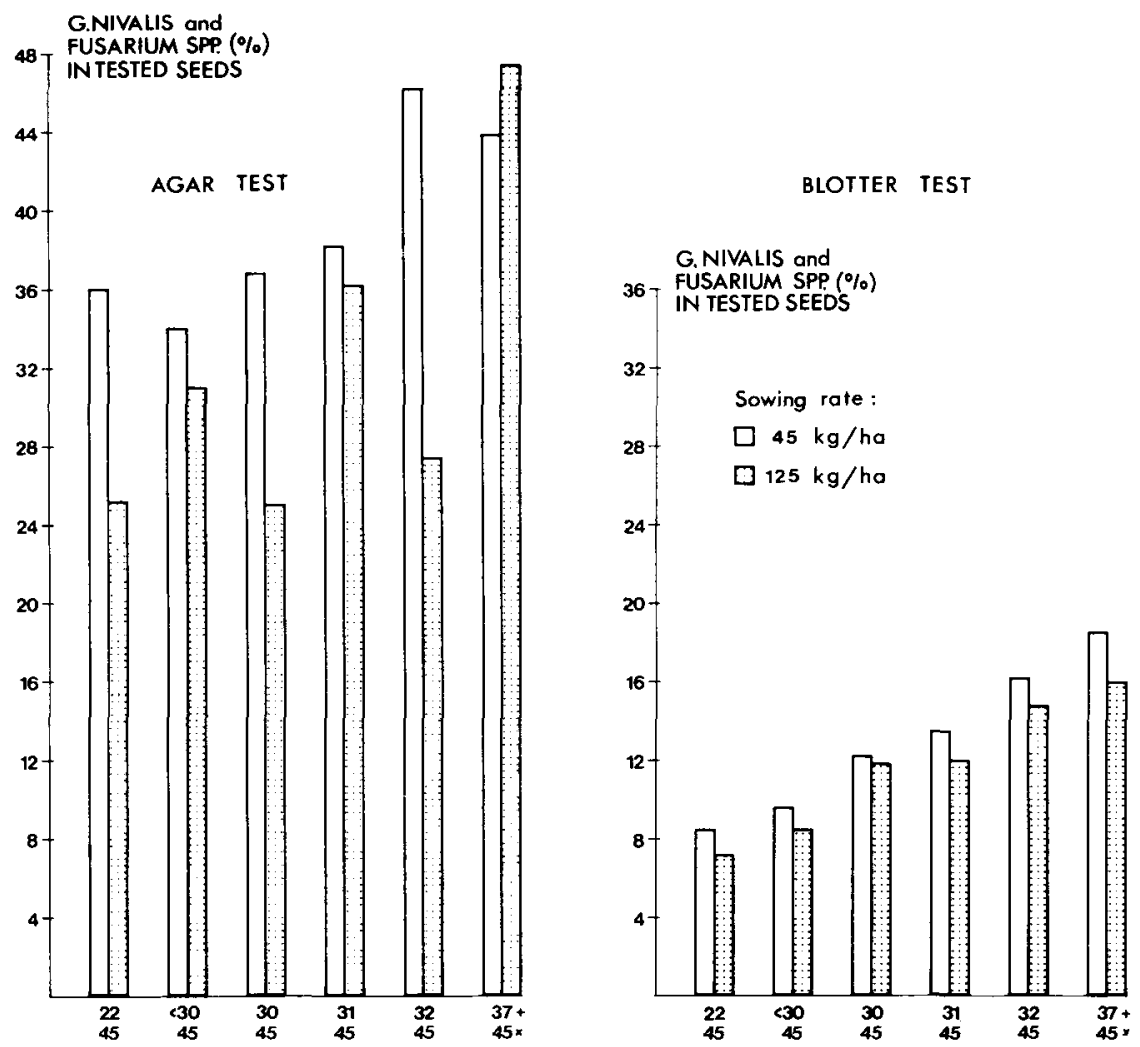

Fig. 1. Increase in Gerlachia nivalis and Fusarium spp. according to plant densities and time of nitrogen dressing (blotter test and agar test). * Scale of Zadoks et al. (1974). 
Table 2 . The percentage of flag-leaf sheath and peduncle area infected by G. nivalis and Fusarium spp. (24-7-1980).

\begin{tabular}{|c|c|c|c|c|c|c|c|c|c|c|c|}
\hline \multirow{2}{*}{$\begin{array}{l}\text { Sowing } \\
\text { rate }\end{array}$} & \multicolumn{6}{|c|}{$\mathrm{N}$ treatment } & \multirow[t]{2}{*}{ Mean } & \multirow[t]{2}{*}{ C.V. } & \multicolumn{3}{|c|}{ Fisher test $^{1}$} \\
\hline & $\mathrm{N} 1$ & $\mathrm{~N} 2$ & N3 & N4 & N5 & N6 & & & $\mathrm{S}$ & $\mathrm{N}$ & SXN \\
\hline S1 & 36.3 & 39.3 & 42.0 & 50.8 & 55.3 & 72.5 & & & & & \\
\hline S2 & 28.8 & 51.5 & 26.3 & 61.5 & 41.3 & 48.8 & 40.1 & 29.0 & & & \\
\hline
\end{tabular}

${ }^{1}$ Confidence limits: ${ }^{*}=0.10>\alpha>0.05 ;{ }^{* * *}=0.01>\alpha>0.001$.

Nitrogen fertilization and infection by G. nivalis and Fusarium spp.

A delay in the first $\mathrm{N}$ dressing, as well in the successive $\mathrm{N}$ applications at short intervals later in the crop development (see nitrogen regime) resulted in higher percentages of infection by G. nivalis and Fusarium spp. on the sheaths of the flag leaves, the peduncles (Table 2) and in the grains (Fig. 1). When the number of days from the first $\mathrm{N}$ dressing until the date on which the disease was observed was plotted against disease incidence (Table 2$)$ the correlation was $-0.67(P \leqslant 0.001)$. The same number of days was plotted against the $\mathbf{N}$ content of the grains (Table 1), against the grain infection found by the blotter test and that found by the agar test. The resulting correlations were $-0.52(P \leqslant 0.01),-0.95(P \leqslant 0.001)$ and $-0.63(P \leqslant 0.01)$, respectively. When the disease incidence (Table 2 ) was correlated with the grain infection found by the blotter test and with the grain infection found by the agar test,

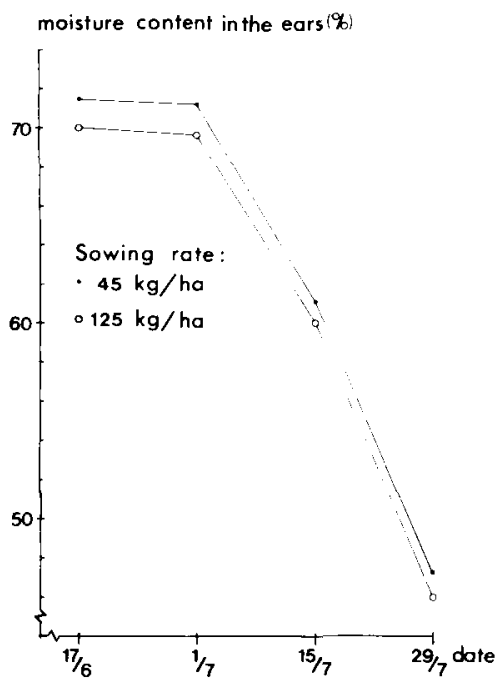

Fig. 2. Decrease in moisture content in the ears at two plant densities. Average of all $\mathrm{N}$ dressings. 
the resulting values were 0.64 and $0.69(P \leqslant 0.01$ for both), respectively. According to the blotter test, the range in grain infection between the treatment that received the first $\mathrm{N}$ dressing in stage 22 and the treatment that received the first $\mathrm{N}$ dressing in stage 37 was $8.5 \%$ to $18.5 \%$ for the low plant density (S1) and $7.3 \%$ to $16.0 \%$ for the high plant density (S2). According to the agar test the range in grain infection for $\mathrm{N} 1$ and $\mathrm{N} 6$ at low (S1) and at high (S2) plant density was $36.0 \%$ to $43.8 \%$ and $25.3 \%$ to $47.5 \%$, respectively.

\section{Discussion}

G. nivalis and Fusarium spp., classified as weakness fungi on wheat by Ubels (1981), attacked in our experiments the sheaths of the flag leaves, the peduncles and the grains (Table 2; Fig. 1). In contrast to the findings of Ubels an increase in plant density resulted in a lower degree of infection. Both a lower moisture content of the ears and shoots, a lower $\mathbf{N}$ content in stems + leaves (Ellen, 1987) and a higher level of water-soluble carbohydrates (WSC) in S2 (Ellen, 1987) may have been the reason for this. The WSC levels, however, were lower than previously reported (Spiertz \& Ellen, 1978; Spiertz \& van de Haar, 1978). This was probably caused by relatively low radiation and heavy rainfall over a period of two months (last week of May, June and July).

The low WSC content also indicate that plants were exhausted of WSC, relatively early giving thereby to $G$. nivalis and Fusarium spp. more chances to infect the plants. Furthermore, a decreasing resistance in the plants, following relatively low production and relatively high transport of assimilates from the vegetative plant parts to the grains, could also have favoured infections of the grains. Velikovský (1964) and Millar \& Colhoun (1969) also found a more severe infection of Fusarium nivale (syn. G. nivalis) when there was much precipitation and many rainy days occurred, conditions that are synonymous with poor light and lower temperatures. That therefore depresses net photosynthesis (Spiertz, 1977).

The relation between the WSC content of the vegetative plant parts and the $G$. nivalis and Fusarium spp. infections of the vegetative and the generative plant parts could not be unambiguously demonstrated. Only the amount of WSC per shoot on 15 July and the percentage of grains infected by $G$. nivalis and Fusarium spp., as determined by the agar test, showed some positive correlation $(r=0.39, P \leqslant 0.05)$. From stage 39 (27 May) until the beginning of grain filling (17 June) the WSC content, averaged over the plant densities, decreased by about $10 \%$ (Ellen, 1987). The amount of WSC in $\mathrm{g} / \mathrm{m}^{2}$ increased little during this period. Consequently, at the beginning of grain filling the WSC level in the plants was low, with small differences between the $\mathrm{N}$ treatments.

It appears that the nitrogen regime can influence the infection by $G$. nivalis and Fusarium spp. The greater the infection of the sheaths of the flag leaves and of the peduncles (Table 3), the greater the infection of the grains was (Fig. 1). The correlation between $\mathrm{N}$ levels in the grains and levels of infection was low for the blotter test data $(r=0.44 ; P<0.05)$ and there was not a correlation with the agar test data.

The levels of $G$. nivalis and Fusarium spp. as found in the blotter test are lower 
than those determined in the agar test. This can be explained by the differences in sensitivity of these tests. Seeds with low levels of inoculum may show outgrowth of the fungi on agar, whereas such inoculum potential is too low for symptom development in the blotter test.

When the $\mathrm{N}$ content in $\mathrm{mg} / \mathrm{shoot}$ (straw and grains) was compared with the infection of the grains for the blotter test data and the agar test data, the correlations were 0.50 and 0.52 ( $P \leqslant 0.05$ for both), respectively. The longer the first $\mathrm{N}$ dressing or the supplementary fertilizations were postponed, the higher was the infection by G. nivalis and Fusarium spp. This suggests that there is a link between the time of first $\mathbf{N}$ dressing, the higher infection in the sheaths of the flag leaves and peduncles, and the greater number of infected grains. Experiments of Smiley et al. (1972) suggested that the application of different types of nitrogen fertilization in the field also boosted infection by Fusarium spp. causing foot rot.

Nitrogen stimulates a more rapid transport not only of nutrients but also of WSC through the vascular system (Lambers et al., 1982). Carbohydrate levels inevitably fall (Ellen, 1987) under conditions of high precipitation and lower light and temperatures during grain filling, i.e. a lower production by the green plant parts at the time, as the demand for WSC was high in the developing grains.

Although in our experiment the applied nitrogen regime seems to be the direct cause for the severe fungal infections, it could also be that the fungi are stimulated by nitrogen in another way. Higher $\mathrm{N}$ contents cause lower sugar contents in the vacuoles of the cells and consequently lower dry matter contents of the plant organs. Lower dry matter contents in turn cause lower specific leaf weight in $\mathrm{mg} / \mathrm{cm}^{2}$ and therefore thinner leaves. Such leaves are probably easier for fungi to penetrate, because of a thinner epidermis.

Ubels (1981) has described the morphology and physiology of Fusarium spp. as well as their occurrence on roots, stems, leaves and ears, and the symptoms and damage they can cause. According to his findings, severe infections can halve yields. In our experiment, damage was mainly expressed in a lower grain weight for a constant number of grains per $\mathrm{m}^{2}$ (Ellen, 1987) and thus a lower grain yield in $\mathrm{kg} / \mathrm{ha}$. When Fusarium culmorum was present, Häni (1977) observed a strong decrease in grain number and grain weight per ear. Infection by $G$. nivalis gave a lower grain weight. The latter observation agrees well with our findings.

In the present study the degree of infection in the main stem was not determined separately from that in the tillers. In our experiment the tillers stayed green longer than usual and therefore the change of the infection, being more severe, was enhanced because the substrate needed by the fungi for their development remained available for a longer period.

The findings from the present experiment suggest that if a widespread infection of foot rot is found in the seed grain crop at an early stage of crop development, it would be advisable to seed producers to apply nitrogen only in early stages of plant development (Fig. 1). This may considerably reduce the transmission of G. nivalis and Fusarium spp. via the new seeds. 


\section{Acknowledgements}

We are greatly indebted to Professor L. J. P. Kupers, Dr J. H. J. Spiertz, Ir E. Ubels and Professor J. C. Zadoks for their valuable criticism and to René de Bont for carrying out the experiments with the seeds. We thank Mr J. S. de Block for translating the manuscript.

\section{References}

Cook, R. J., 1968. Fusarium root and foot rot of cereals in the Pacific Northwest. Phytopathology 58: 127-131.

Cook, R. J. \& A. A. Christen, 1976. Growth of cereal root-rot fungi as affected by temperature-water potential interactions. Phytopathology 66: 193-197.

Cook, R. J., 1980. Fusarium foot rot of wheat and its control in the Pacific Northwest. Plant Disease 64 (12) 1061-1066.

Ellen, J., 1987. Effects of plant density and nitrogen fertilization in winter wheat (Triticum aestivum L.). 1. Production pattern and grain yield. Netherlands Journal of Agricultural Science 35: 000-000.

Forrer H. R., F. H. Rijsdijk \& J. C. Zadoks, 1982. Can mildew assist in the entry of Fusarium fungi into wheat leaves? Netherlands Journal of Plant Pathology 88: 123-125.

Gams, W. \& E. Muller, 1980. Conidiogenesis of Fusarium nivale and Rhynchosporium oryzae and its taxonomic implications. Netherlands Journal of Plant Pathology 86: 45-53.

Häni, F. J., 1977. Ueber Getreidefusariosen, insbesondere Fusarium nivale (Fr.) Ces. bei Weizen und Roggen. Dissertation, Eidgenossische Technische Hochschule Zürich, No 6092, 60 pp.

Hewett, P. D., 1965. A survey of seed-borne fungi of wheat. Transactions British Mycological Society 48: 59-72.

Lambers H., R. J. Simpson, V. L. Beilharz \& M. J. Dalling, 1982. Growth and translocation of C and N in wheat (Triticum aestivum) grown with a split root system. Physiologia Plantarum 56: 421-429.

Millar, C. S. \& J. Colhoun, 1969. Fusarium diseases of cereals. IV. Observations on Fusarium nivale on wheat. Transactions British Mycological Society 52 (1): 57-66.

Millar, C. S. \& J. Colhoun, 1969. Fusarium diseases of cereals. IV. Epidemiology of Fusarium nivale on wheat. Transactions British Mycological Society 52 (2): 195-204.

Richardson, M. J. \& F. J. Zillinsky, 1972. A leaf blight caused by Fusarium nivale. Plant Disease Reporter 56 (9) 803-804.

Smiley, R. W., R. J. Cook \& R. I. Papendick, 1972. Fusarium foot rot of wheat and peas as influenced by soil applications of anhydrous ammonia and ammonia-potassium azide solutions, Phytopathology 62: 86-91.

Spiertz, J. H. J., 1977. The influence of temperature and light intensity on grain growth in relation to the carbohydrate and nitrogen economy of the wheat plant. Netherlands Journal of Agricultural Science 25: 182-197.

Spiertz, J. H. J. \& J. Ellen, 1978. Effects of nitrogen on crop development and grain growth of winter wheat in relation to assimilation and utilization of assimilates and nutrients. Netherlands Journal of Agricultural Science 26: 210-231.

Spiertz, J. H. J. \& H. van de Haar, 1978. Differences in grain growth, crop photosynthesis and distribution of assimilates between a semi-dwarf and a standard cultivar of winter wheat. Netherlands Journal of Agricultural Science 26: 233-249.

Strange, J. N. \& H. Smith, 1971. A fungal growth stimulant in anthers which predisposes wheat to attack by Fusarium graminearum. Physiological Plant Pathology 1: 141-150.

Ubels, E., 1981. Fusarium in tarwe. Gewasbescherming 12 (4): 105-124.

Velikovský, V., 1964. Discertacní práce Fusarium nivale u zita. (Translation of summary and conclusions.) Pudoc, Wageningen, 12 pp.

Zadoks, J. C., T. T. Chang \& C. F. Konzak, 1974. A decimal code for growth stages of cereals. Weed Research, 14: 415-421. 